\title{
Rescue, revive, rejuvenate: The new science of ex vivo lung perfusion
}

\author{
Ross M. Bremner, MD, PhD
}

\author{
From the Norton Thoracic Institute, St. Joseph's Hospital and Medical Center, Phoenix, Ariz. \\ Disclosures: Author has nothing to disclose with regard to commercial support. \\ Received for publication Oct 12, 2016; revisions received Oct 12, 2016; accepted for publication Oct 12, 2016; \\ available ahead of print Nov 9, 2016 \\ Address for reprints: Ross M. Bremner, MD, PhD, Norton Thoracic Institute, St Joseph's Hospital and Medical \\ Center, 500 W. Thomas Rd, Ste 500, Phoenix, AZ 85013 (E-mail: Ross.Bremner@ DignityHealth.org). \\ J Thorac Cardiovasc Surg 2017;153:205 \\ $0022-5223 / \$ 36.00$ \\ Copyright (C) 2016 by The American Association for Thoracic Surgery \\ http://dx.doi.org/10.1016/j.jtcvs.2016.10.016
}

It is an exciting time to be involved with lung transplantation. For years we have been frustrated by the high rate of refusal of donated lungs deemed unacceptable for transplant because of edema, contusion, infection, or diminished function. In fact, as pointed out by Mehaffey and colleagues, ${ }^{1}$ only $15 \%$ of lungs from organ donors are ultimately transplanted. Although we have learned that we can use more "marginal" donor organs, a large number are still turned down. Furthermore, the incidence of primary graft dysfunction in transplanted lungs remains a significant problem. Primary graft dysfunction translates to increased chronic rejection and poorer overall long-term survival. Enter the world of ex vivo lung perfusion (EVLP). Organs can now be harvested and then placed on a circuit that perfuses and ventilates the organ. Different systems are being investigated, but the primary goals of this modality are (1) better preservation of the organ to improve its function once implanted and (2) the ability to salvage organs for transplant that would otherwise be deemed unacceptable. Early reports have shown that both goals can be met, which will expand the donor pool, decrease waitlist mortality, and-hopefully-improve long-term organ function after transplantation.

The current study questions whether the mode of ventilation of EVLP after donation after circulatory death affects the organ's function after transplantation. This is an innovative question, because little is understood regarding ventilatory strategies of the lung during EVLP outside the confines of the chest cavity. The potential for overdistention and barotrauma is significant, because compliance outside the chest is naturally different. Mehaffey and colleagues ${ }^{1}$ investigated the use of airway pressure release ventilation (APRV) during EVLP. This approach may offer advantages, such as alveolar recruitment, enhanced oxygenation, and attenuation of barotrauma. The strategy was used after a significant period (ie, 2 hours) of warm ischemia in a donation after circulatory death porcine model. The organs were evaluated on the EVLP circuit and then again after transplantation in a live animal. The authors found that this

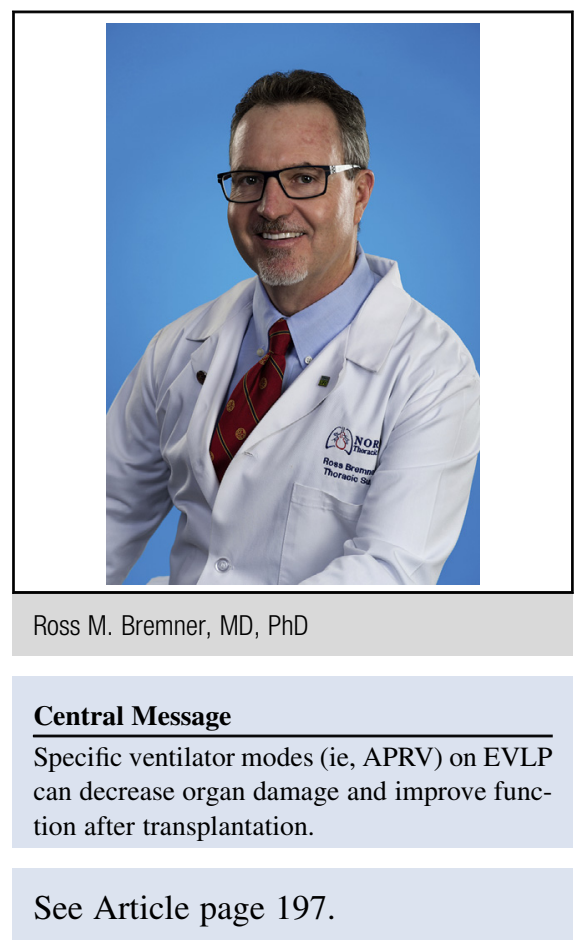

approach significantly improved compliance and lung oxygenation after transplantation. Mehaffey and colleagues ${ }^{1}$ demonstrated that APRV reduced the development of lung edema on EVLP and found no difference in accumulation of additional edema 4 hours after reperfusion. Their cytokine analysis, which was performed at different time points, showed a significant decrease in interleukin-6 and 12, with fewer neutrophils in the APRV transplanted lungs.

The results of the study are impressive. Undoubtedly, more work must be done to determine the optimal setting for APRV, but this study likely can be translated to the clinical realm. It is also impressive that residents performed these experiments and that more than 50 porcine transplants were performed by 2 residents over just 2 years. These young surgeons have an exciting future in the science of EVLP. Meanwhile, the senior authors are to be congratulated not only for progressing the science of EVLP but also for mentoring these future surgeon scientists who will help us rescue and revitalize organs more effectively in the years to come.

\section{Reference}

1. Mehaffey JH, Charles EJ, Sharma AK, Money DT, Zhao Y, Stoler MH, et al Airway pressure release ventilation during ex vivo lung perfusion attenuates injury. J Thorac Cardiovasc Surg. 2017;153:197-204. 